\title{
THE APRIL MEETING IN STANFORD UNIVERSITY
}

The four hundred tenth meeting of the American Mathematical Society was held at Stanford University on Saturday, April 28, 1945. Approximately forty people attended, including the following twentyeight members of the Society:

H. M. Bacon, B. A. Bernstein, H. F. Blichfeldt, E. A. Davis, T. C. Doyle, Evelyn Fix, S. M. Hallam, O. H. Hamilton, J. G. Herriot, Glenn James, D. H. Lehmer, J. C. C. McKinsey, F. J. Massey, E. D. Miller, K. A. Morgan, Jerzy Neyman, C. D. Olds, George Polya, W. C. Randels, J. B. Robinson, R. M. Robinson, S. A. Schaaf, A. C. Schaeffer, T. W. Simpson, Gabor Szegö, Alfred Tarski, A. R. Williams, František Wolf.

There was a section for contributed papers in the morning at which Professor B. A. Bernstein presided. The afternoon session was devoted to a symposium on Contagious probability distributions at which Professor Jerzy Neyman and Professor George Polya spoke. Professor Polya spoke about Interpretation or interpolation? Remarks on certain applications of, and certain views about, contagious probability distributions. This address discussed some of the known dependent events ("influence of the crowd," "influence of the predecessor," and so on), their most intuitive applications, and the notable fact that a probability distribution resulting from such a structure of mutual dependence can be interpreted also as generated by the concurrence of independent events, and even in various ways (inhomogeneity, delivery by "packages"). Professor Neyman's address, which will be printed in greater detail, was about Multivariate Poisson and contagious distributions. Professor H.F. Blichfeldt presided at the afternoon session.

Titles and cross references to papers read at the meeting follow below. Paper 7, whose abstract number is followed by the letter $t$, was read by title. Mr. Jonsson was introduced by Dr. Tarski.

1. D. H. Lehmer: On the Graeffe process for power series. (Abstract 51-5-87.)

2. Kathryn A. Morgan: Representation of a positive binary form by a positive quaternary form. (Abstract 51-5-81.)

3. R. M. Robinson: Univalent majorants. (Abstract 51-5-89.)

4. Glenn James: Certain general polynomial expansions. (Abstract 51-5-86.)

5. George Polya and Gabor Szegö: On finite Fourier integrals. (Abstract 51-7-119.)

6. Bjarni Jonsson: On unique factorization problem for torsionfree Abelian groups. (Abstract 51-5-75.) 
7. E. R. Lorch: The Cauchy-Schwarz inequality and self-adjoint spaces. (Abstract 51-3-64-t.)

\author{
A. C. Schaeffer, \\ Associate Secretary
}

\title{
REPORT OF THE MEETING OF THE COUNCIL OF THE SOCIETY IN NEW YORK CITY ON APRIL 28, 1945
}

A meeting of the Council of the Society was held in the Men's Faculty Club at Columbia University at 1:30 P.M. on Saturday, April 28, 1945. The following members of the Council were present: A. A. Albert, Garrett Birkhoff, S. S. Cairns, Richard Courant, Arnold Dresden, B. P. Gill, M. R. Hestenes, T. R. Hollcroft, Harold Hotelling, Saunders MacLane, J. F. Ritt, P. A. Smith, I. S. Sokolnikoff, J. D. Tamarkin, Hassler Whitney, and the Secretary.

Certain papers submitted for presentation at various meetings of the Society were read by title at the meeting of the Council; titles and cross references to the abstracts of these papers appear at the end of this report.

The Secretary announced the election of the following ten persons to ordinary membership in the Society:

Mr. Silvio Aurora, Columbia University;

Professor Harold Frederick Bright, University of Rochester;

Miss Helen M. Clark, Northwestern University;

Dr. Vincent Frederick Cowling, Rice Institute;

Mrs. Anne Carples Davis, Seaman Second Class, U.S.N.R.;

Mr. Richard Latter, Lieutenant, U.S.N.R.;

Mr. Douglas Blakeshaw Netherwood, Captain, A.U.S.;

Mr. Joseph Thomas Olsztyn, Private, U.S.A.;

Mr. Clarence A. Phillips, University of Illinois;

Mr. Marlow Canon Sholander, Brown University.

The Department of Mathematics of the University of Oregon was elected to institutional contributing membership.

The following appointment by the President was reported: as a Committee to Select Gibbs Lecturers for 1946 and 1947, Professors L. M. Graves (Chairman), G. A. Hedlund, and S. S. Wilks.

It was reported that the Board of Trustees had approved the recommendation of the Council that a catalogue of the Society library be published during 1945 and that the Board had appropriated $\$ 2500$ for this purpose. 